\title{
'The new attractive mine': 36 research areas for attractive workplaces in future deep metal mining
}

\author{
Bo Johansson and Jan Johansson* \\ Centre of Advanced Mining and Metallurgy, CAMM, \\ Department of Human Work Science, \\ Luleå University of Technology, Sweden \\ E-mail: Bo.Johansson@1tu.se \\ E-mail: Jan.Johansson@ltu.se \\ ${ }^{*}$ Corresponding author
}

\begin{abstract}
Future efficient mining operations will be dependent upon a highly competent and well motivated work force, on all levels. The mining companies will have to recruit their personnel from a limited group of talented individuals with high demands and expectations on future work. In order to be successful with this, the companies must offer attractive workplaces that are safe, sound, interesting and can offer challenging work tasks too. In this paper we discuss a number of potential challenges for the future mining industry based on the fact that the majority of the mines are expected to be deeper and located in remote areas. Our intention is to illustrate a possible way forward for the mining industry. We start by describing a vision for such a safe and attractive mine. After that we present a comprehensive and possible research agenda necessary for creating the 'New Attractive Mine'.
\end{abstract}

Keywords: research agenda; future; underground; mining; attractive workplace; automation; health; safety; risk; work environment.

Reference to this paper should be made as follows: Johansson, B. and Johansson, J. (2014) "The new attractive mine': 36 research areas for attractive workplaces in future deep metal mining', Int. J. Mining and Mineral Engineering, Vol. 5, No. 4, pp.350-361.

Biographical notes: Bo Johansson is an Associate Professor in Human Work Science at Luleå University of Technology. His research is mainly within the field of work environment management, work environment, and industrial production development. He has an MS in Mining Engineering and a $\mathrm{PhD}$ in Human Work Sciences. He has previously worked as a Mining Engineer and Head of a mine planning division at Boliden Minerals. At Luleå University of Technology he has been Director of Studies and Programme Coordinator.

Jan Johansson is Professor in Human Work Sciences at Luleå University of Technology and Head of the Department of Business Administration, Technology and Social Sciences. His research is located within the Centre of Advanced Mining and Metallurgy. He is active in both the Swedish-Polish project The Smart Mine of the Future and in the European project Innovative Technologies and Concepts for the Intelligent Deep Mine of the Future. 


\section{Introduction}

This paper is the third in a series dealing with future mining. The empirical material is taken from two studies dealing with future mining: $I^{2}$ Mine (EU-FP7) and The Smart Mine of the Future. The other two papers are Future of Metal Mining: Sixteen Predictions (Abrahamsson et al., 2009) and Attractive Workplaces in the Mine of the Future: 26 Statements (Johansson et al., 2010).

\section{Background}

The world's metal mining industry faces a number of challenges which must be managed wisely. The most obvious challenge is to produce at costs that are determined in international competition, meaning that all mining companies are under increased pressure for further rationalisation that requires both new technologies and new organisational solutions (Hancock and Sinclair, 2008). The long-term challenges also include environmental issues and impacts of the Kyoto Protocol. This will require significant investments in acquisition of emission allowances. An increasing share of the total mining production will be by underground mining where ore will be hoisted from gradually deeper mines (Hancock and Sinclair, 2008; Lane et al., 2008).

Mining at increased depths can cause a number of problems that often can be very difficult and expensive to solve or manage. One of these problems is the stress increase by either the increased gravitational weight of the overlaying rock or due to high tectonic (horizontal) stresses and how stresses affect the rock masses surrounding all excavated openings, tunnels, shafts, ramps etc. The heavier load results in an increased risk for rock falls and rock bursts due to induced seismic activity (Seedsman, 2011). The consequences can vary from minor to devastating and much effort must therefore be paid to reduce the present risks, both proactively and reactively. Qualified expertise on rock mechanics and rock reinforcement should always be engaged in early mine design and further on all the way into production phases so that the risks can be minimised.

A second significant problem is increased bedrock temperature at depth. On average the temperature increases with about $25^{\circ} \mathrm{C}$ for each $1000 \mathrm{~m}$ (Fridleifsson et al., 2008). The warm bedrock heats up the air causing a heat stress on underground personnel if air cooling is not available. Cooling measures are very expensive but necessary if miners working hours are not to be drastically reduced.

A third obvious depth-related problem is logistics associated with, for example, prolonged transportation distances and transport time which reduces the effective working hours for the miners causing higher labour costs per ton mined ore and makes fast emergency and rescue transports more difficult to achieve. In the large El Teniente new mine level project there was, for example, a strong demand from the project manager to find design solutions to this problem that they had with the old transport system (Revuelta et al., 2008).

The rest of the work environment conditions in the deep mines are quite similar to more conventional underground more shallow mines, which still in most media is described as "dark, dirty, and dangerous". 
An important component of attractive work places is a safe environment. In underground mining the basic solution must be to distance the miners from the physical mining front and locate them in a safer environment (Noort and McCarthy, 2008). Remote control, automation, and new mining techniques are major challenges and possibilities, but it is also a matter of relevant education, rules, and good practices (Bassan et al., 2008; Abrahamsson et al., 2009; Bäckblom et al., 2010).

Another challenge is the problem of recruiting skilled workers to the mines often located far from larger communities. A modern mine is so technically advanced that the proportion of unskilled labour will decrease significantly or disappear (Hebblewhite, 2008; Scoble and Laurence, 2008). A further challenge is to break the unequal gender balance that exists in most mines. It is not just about recruiting more women, but rather to challenge the prevailing macho culture in order to create a safer and more productive environment (Abrahamsson and Johansson, 2006, 2008).

To conclude, the deep metal mining industry will probably face major challenges that require extensive research and immediate action. Problems interact with each other in such a way that the solutions require a holistic perspective, where both technical and social factors are taken into consideration when solutions are formed and decided (Johansson et al., 2011). We will now continue our analysis by first presenting a hypothetical future mine, which we are referring to in this paper as 'The New Attractive Mine'. This vision is inspired by research on different potential aspects of future mining presented by among others, Gipps and Cunningham (2011), Gipps et al. (2011), Horberry et al. (2011) and Mottola et al. (2011).

\section{3 'The new attractive mine': a vision for 2030}

The new deep metal mine was a true planning and cooperation success and a huge leap in mining history. A number of leading 'European mining companies' had been inspired by a group of 'Australian researchers' that had provided a conceptual system for automated and flexible mining, based on drill and blast technology for fragmentation of the actual ore. Continuous mining with road headers was still only used in development works where conventional drilling and blasting was abandoned. The zero entry mine was now almost realised and the large "European manufacturers of advanced mining equipment" had contributed largely to the technological success, which had opened a new global market for them.

The new automated mining method made it possible to almost continuously produce desired ore qualities and quantities on customers' demand. This was a big comparative advantage compared to the old traditional bulk production mines that still existed and struggled for their survival. The new mining system dramatically reduced the prevailing and traditional use of expensive storing and stacking of mined ore. With the new way to mine an important first step towards true Lean-mining was taken and gradually one bottleneck after another was discovered and eliminated. Metal recovery was very high and cut-off grades were reduced. It seemed as if traditional mining had been a real waste of resources.

Advanced investment analyses had clearly shown that there were great financial benefits with the new automated mining technology. The costs for underground development works were reduced with about $50 \%$ compared with traditional mining methods and labour costs were reduced to much more than that. This made it possible for 
the companies to make large investments in new technology and personnel competence and still be highly profitable. If profits for society and individuals also were included in the analysis the total expected financial benefits were overwhelming. Follow-up of actual economical results showed even bigger savings than expected.

An unusual feature of the new mine was that open pit mining was avoided although the upper parts of the ore body were close to the surface. A green mining philosophy 'In situ mining' was applied and most of the mining activities were invisible to people passing through the mine site. Most of the waste material was directly used for backfill after recovering the metal content.

The mining companies had from the start of the project made use of a newly developed iterative planning methodology that reduced common initial design errors when they designed the new mine. Basic guidelines provided very useful demands for the mine designers. During the development works there had, for example, never been any real ventilation problems, stability problems, or water drainage problems. No severe accidents or incidents had occurred so far and all mining activities were systematically risk assessed. The new mine had set a new world standard for results regarding health and safety results. Safety first was not only a simple slogan, it was a complex and applied reality. In fact no major physical work or main activities were performed unless they had been computer simulated, evaluated, and approved. This proactive way to handle production and safety risks had proven its value time after time. The old description of mining work as "dark, dirty, and dangerous" had definitively become out of date and irrelevant. Instead of being almost unpredictable and uncertain mining had become highly predictable. Some of the old miners felt that the original charm of mining was somewhat lost when all worked according to plan, but no one really wanted the old risky ways and days back.

One key to the success was the fact that the mine was already from the start designed for automation and socio-technical principles, with a work organisation based on production teams and broad professional skills among management and miners. One of the mines' most impressive features was the information and decision systems based on sensor technology and production analysis in real time. This made it possible for the personnel to actively steer and control the production instead of just passively reacting on deviations and alarms from an automated production process. This was a major difference and advantage compared with traditional control room work in, for example, regular processing plants. Impressive results regarding product quality and production availability and stability had been achieved due to this proactive philosophy. The philosophy also made the miners' work interesting and challenging.

The new remote operations control centres (ROCs) were designed to promote cooperation and creative problem solving in multi-skilled teams. The working teams were mixed regarding age, experience, gender, competence, etc. Diversity had replaced conformity and this had proved to be a good base for creating 'production scouts', miners that were always ready and interested in improving the mining processes. Most of the team members were recruited from national and regional education programmes that were specially developed with regard to the new demands that the mining sector had, basically that modern mining was an intellectual analytical work for wise and reliable persons. New education programmes on all levels had been started and were recruiting well. Mining work had turned to be attractive, not only because of the wages, but also because it was a very interesting work with good possibilities for personal and professional development in a safe and sound working environment. 
The total progress had been astonishing although they only have started to utilise parts of the potential that the new technology and organisation offered. Investments in research and development work had paid off quickly and management were convinced that innovative R\&D combined with a challenging vision had been and would continue to be the key factor for success.

\section{Way forward: 36 strategic areas for research, development, and innovation}

Visions are important since they direct and motivate strategic research, development, and innovation. Based on the vision above we are therefore going to present and discuss a number of important strategic areas for further research, development, and innovation that in one way or another clearly will affect the attractive workplace in future deep metal mining.

\subsection{Early mine design}

Many problems in the work environment in present mines (and in other industries as well) can be traced back to insufficient initial physical planning and design. Since mining is characterised by huge investments and long-term operations it is very important to have a well designed physical production system. The physical layout also influences and limits the organisational aspects. If initial mistakes are made the personnel will have to face the negative consequences for many years to come. The initial design phases of every major development project are therefore critical for establishing a safe and attractive physical and psycho-social work environment in a mine.

The main idea and research task in this challenge is to combine and further develop a general iterative industrial planning and design method (Ranhagen, 1995) with available and relevant work environment tools (Neumann, 2006) and combine them with an overarching Lean production philosophy (Liker, 2004) in a metal mining context (see Figure 1). The final product, that is planning guidelines with focus on work environment design in underground mines, shall be adapted to the users' (pre-study engineers, feasibility engineers, project planners, automation engineers, layout planners, ventilation planners etc.) needs and professional situation. Such guidelines, preferably integrated with CAD-planning and design tools, would help these professional to create more safe and attractive workplaces in future mines.

Special attention needs to be paid to different aspects of automation, which is a strong trend in mining, and can have great impact, both positive and negative, on the work environment (Widzyk-Capehart and Duff, 2007; Noort and McCarthy, 2008; Johansson, 2010). Designers of mine productions systems also have quite a lot of legislation and compulsory provisions to regard as well as company specific rules and standards for the work environment and the management of health and safety (Johansson and Johansson, 2008). These aspects must also be integrated in the guidelines for work environment planning and design. 
Figure 1 Cyclic iterative planning when conditions are complex

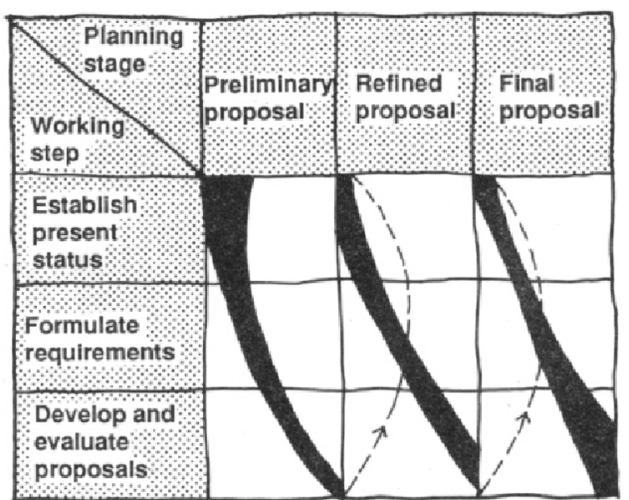

Source: Based on Ranhagen (1995)

The major research task can be described as:

- development of alternative guidelines for early and critical stages of future deep mine design.

\subsection{Mining methods}

The choice of the mining method defines in an essential way the framework for health and safety matters. A method that allows zero entry to face front offers completely new opportunities in safety than the methods in which the work must be carried out in potentially unsafe zones. A development of continuous mining methods is therefore the measure that has the potential to give the best exchange in health and safety. Continuous mining opens up new possibilities for remote control, automation, and production according to Lean mining.

In parallel with research on continuous mining there is a need for development of the more conventional mining methods towards improved safety. Non-entry mass mining methods must be developed and there is a need for safer methods for recovery mining of pillars in room and pillar mining as well as in different variants of cut and fill mining. Rock mechanic research will play an important role in this research.

Three major research fields are consequently:

- development of continuous mining methods for hard rock

- development of safer underground mass mining methods

- development of safer methods for recovery mining of pillars.

\subsection{Automation of mining operations}

By automation of mining operations we mean that the miners work and intervention in these operations has been completely or almost completely replaced with work controlled and performed by machines. 
Detailed visions of different levels of remote control and automation in deep metal mining need to be developed so that safety and health effects of automation can be analysed.

Such detailed visions should however be preceded by a number of holistic economic analyses that will show the economic frames for investments in automation technology that will be opened due to reductions in mining and labour costs. What sums will be available for investments in automation technology if $100 \%$ of the underground personnel are removed? Will the money be enough for the needed investments? What money will be available if the reduction in personnel is $80 \%$ ? Such economic analyses will roughly show the economic limits for automation and set the frames for the detailed visions, that is the more detailed pictures of future more automated and remote-controlled mining.

When the different visions are specified a systematic analysis of the pros and cons of automation of different unit operations should be performed in terms of risks for accidents, poor ergonomics, noise, dust, vibration, heat etc. How much better and safer working environment can you get through automation? What new risks will arise? What old risks will fall off? Based on such fundamental analysis more specific development projects can be identified.

In conclusion, we see three areas of research regarding automation:

- an economic holistic evaluation of various levels of automation that will show the economic frames for automation of underground mining

- development of detailed visions of different levels of automation underground

- a systematic review and quantification of the health and safety advantages and disadvantages of different levels of automation.

We can also identify a number of technical areas of evolutionary development that has important implications for health and safety:

- development of unmanned remote-controlled continuous mining equipment

- development of techniques for remote-controlled backfilling techniques that match systems of remote-controlled continuous mining

- development of techniques for automation of explosives charging for mass mining, selective mining, and drifting

- development of remote control of scaling equipment and automated scaling

- development of techniques for automation of loading and transport with LHD machines, also in small-scale mining

- development of humanoids (remote-controlled and automatic robots) to perform especially high-risk and demanding tasks.

The history of automation shows that it must be regarded as the main alternative for increasing safety in future deep mines. Automation projects still need to be critically evaluated since there is no absolute correlation between automation and improved safety. 


\subsection{Remote operations centres (ROC)}

The other side of the coin is the control centres that can be above or below ground. An important area of research is what happens to the job when you move it to the ROC (Bassan et al., 2008). What new skills are needed and how will these skills be maintained when you no longer have direct contact with the rock? How shall process information be presented to the operators? What will be decided by the operators and what will be decided by the automatic decision systems? There are a number of development projects that affect the job content. We therefore want to emphasise the following research and development areas:

- research about job content for personnel working in the ROCs

- development of visualisation system for ROCs, where the entire value chain can be seen and controlled

- development of automated decision systems for ROCs, especially simulation of critical operations.

\subsection{Work environment, health and safety}

As we mentioned earlier the zero entry mine is a vision for future mining; even if we are aware of this we can't get there in a reasonable near future. We must accept that there will still be a lot of underground workers in the nearest future and their jobs must be safe. This is a challenge that can be broken down into a series of research and development projects.

A solution that has been discussed above is vehicles with fully secure cabins. Can they be designed so that both safety and weight demands are fulfilled? What jobs can be done from the cab? What cannot be performed from the cab? How far can you develop the idea with security cabs compared with some already existing cabins?

Another important area is communication system for increased security and productivity where the operators are in constant real-time contact with each other and with the production management through voice and picture. Miners equipped with minicameras could for everyday and emergency situations provide their colleagues and senior management with information that is difficult to convey verbally. Different types of minisensors worn by the miners could contribute further useful information.

Mining at increased depths means working in an environment that gradually becomes hotter. In some mines the heat load already is a difficult and large problem that will increase in the future.

Deeper and horizontally more extended mines will result in intensified underground vehicle traffic with increased risks for traffic accidents and air pollution. This is clearly already a significant problem that will grow in the future if nothing drastic is done.

However, probably the most important safety project is to keep the vision of the zero entry mine alive. Maybe this vision is something that should characterise all projects rather than being a single project. To summarise, we wish to give emphasis to the following research and development projects dealing with the idea of zero entry:

- development and maintenance of a vision for the zero entry mine

- development of multimedia communication systems that are worn and used by all 
- development of technologies for climate control and ventilation in deep mines; reducing the heat load for employees

- development of mining vehicles with fully secure 'lightweight' cabins

- development of systems for improved road safety underground (crash protection, run over protection)

- research about and development of engines with low or no toxic gas emissions.

\subsection{Work environment management}

A good working environment requires a strategy for safety management based on early risk assessment. A practical common problem is to foresee and act before something negative happens and not just react after it has happened. There is a need of a number of new indicators in order to operate successfully with work environment in the mine of the future, since the work environment will change radically. There is also a need to expand activities to health promoting activities. Since acompetent workforce will be companies' most valuable asset special efforts will be needed to keep the personnel healthy and well motivated.

- develop proactive methods for better measurement and assessment of major risks, as a complement to the now prevailing lost time injury frequency rate (LTIFR)

- develop indicators of psycho-social work environment in mines, for example, variants of satisfied co-worker index

- develop indicators of health and healthy work environments in mines

- develop tools for risk assessment in strategic decision-making, such as choice of mining method, adapted for top management and the company board

- develop methods for determining the total cost of the work environment in the mining industry, separated on costs for society, companies, and individuals.

In addition to improved indicators and tools there is a need for a couple of cultural changes. Since the workforce will consist of quite a large portion of different contractors, the contractors' health and safety also must be regarded:

- develop a safety culture that challenges the existing macho behaviour and promote a culture where the miner cares about his/her own and others' safety

- develop safety systems and procedures for contractors working in high-risk guest environments; the procedure for buying contractors services will probably be especially interesting.

\subsection{Competence development}

There is a need for new methods for learning at work; this is something both employers and employees want. To guarantee development in one's professional role and inhibit becoming stuck in the demands of a special task requires a certain degree of generalness in competence development. Broad work roles are a classic demand that can also be 
combined with the ideas behind Lean mining. The industry has a general need to recruit more women.

- identify future skill needs and shape future education programmes for mine management and workers

- develop a strategy for recruiting more women

- develop a mentor system for miners so that professional knowledge is transferred between generations

- develop VR for training and simulation, particularly the operations in hazardous environments.

\subsection{Work organisation}

Future mining will be shaped in a context where it is necessary to produce at costs that are determined in international competition. A general effect is that all mining companies are under increased pressure for further rationalisation that requires both new technologies and new organisational solutions (Hancock and Sinclair, 2008). The companies will no longer have clear boundaries. Instead there will be a lot of informal and formal cooperation with suppliers, customers, contractors, competitors, and colleagues (Bassan et al., 2008). The cooperation with contractors will be especially advanced and integrated. Based on these developments, we can see a need for a modern learning work organisation based on Lean production adapted to the human physiological, psychological, social, and cultural conditions:

- develop and adjust the Lean production concept to the conditions in the mining industry

- develop forms of relatively autonomous production teams including contractors

- develop new pay system to encourage both safety and improvement in productivity.

\section{Conclusions}

We have above pointed out 36 areas where there is a clear need for further research and development. Many have a strategic character. Some are comprehensive while others are focused on a few concrete issues, and several issues interact with each other. We have therefore tried to select and gather them in one prioritised research area that is highly strategic and proactive:

"Safety first by development of design criteria and guidelines for good and safe mining work and work places in deep metal mines."

This area is the most strategic long-term area that we are convinced will give the best monetary, humanitarian, and social payback. It deals with eliminating root causes to important design problems as early as possible, before problems become too difficult and expensive to solve. That is why we recommend the mining business to prioritise and invest in this field of R\&D. 


\section{References}

Abrahamsson, L. and Johansson, J. (2006) 'From grounded skills to sky qualifications', Journal of Industrial Relations, Vol. 48, No. 5. pp.653-672.

Abrahamsson, L. and Johansson, J. (2008) 'Work culture and gender issues in a changing technical context - examples from LKAB Iron ore mine in Kiruna', Paper presented at The 5th International Conference on Mass Mining (Mass Min 2008), 9-11 June, Luleå, Sweden.

Abrahamsson, L., Johansson, B. and Johansson, J. (2009) 'Future of metal mining: sixteen predictions', International Journal of Mining and Mineral Engineering IJMME, Vol. 1, No. 3, pp.304-312.

Bäckblom, G., Forssberg, E., Haugen, S., Johansson, J., Naarttijärvi, T. and Öhlander, B. (2010) Smart Mine of the Future - Conceptual Study 2009-2010, Final Report, Nordic Rock Tech Centre, Gällivare.

Bassan, J., Srinivasan, V., Knights, P. and Farrelly, C.T. (2008) 'A day in the life of a mine worker in 2025', Paper presented at The First International Future Mining Conference, November, Sydney, Australia.

Fridleifsson, I.B., Bertani, R., Huenges, E., Lund, J.W., Ragnarsson, A. and Rybach, L (2008) The possible role and contribution of geothermal energy to the mitigation of climate change', in Hohmeyer, O. and Trittin, T. (Eds.): IPCC Scoping Meeting on Renewable Energy Sources, Luebeck, Germany, pp.59-80.

Gipps, I. and Cunningham, J. (2011) 'ROES ${ }^{\circledR}$ - automated rock extraction', Proceedings from Second International Future Mining Conference 2011, 22-23 November, Sydney.

Gipps, I., Cunningham, J., Fraser, S. and Widzyk-Capehart, E. (2011) 'Now to the future - a path toward the future mine', Proceedings from Second international Future Mining Conference 2011, 22-23 November, Sydney.

Hancock, S. and Sinclair, D. (2008) 'Meeting resource constraint demands in future mining to 2050', Paper presented at The First International Future Mining Conference, November, Sydney, Australia.

Hebblewhite, B. (2008) 'Education and training for the international mining industry - future challenges and opportunities', Paper presented at The First International Future Mining Conference, November, Sydney, Australia.

Horberry, T., Lynas, D., Franks, D., Barnes, R. and Brereton, D. (2011) 'Brave new mine examining the human factors implications of automation and remote operation in mining', Proceedings from Second international Future Mining Conference 2011, 22-23 November, Sydney.

Johansson, B. (2010) Work Environment in Future Mining, Sub Report Mine of the Future (MIFU) Work Package \# 3: The Attractive Workplace, Department of Human Work Sciences, Luleå University of Technology, Sweden.

Johansson, B. and Johansson, J. (2008) Work Environment and Work Organization in the Swedish and Finnish Mining Industry, Department of Human Work Sciences, Luleå University of Technology, Sweden.

Johansson, B., Johansson, J. and Abrahamsson, L. (2010) 'Attractive workplaces in the mine of the future: 26 statements', International Journal of Mining and Mineral Engineering. Vol. 2, No. 3, pp.239-252.

Johansson, B., Johansson, J. and Abrahamsson, L. (2011) 'Attractive workplaces in future deep metal mining', Paper presented at The 2nd International Future Mining Conference, 22-23 November, 2011, Sydney, Australia.

Lane, G., Fountain, C. and La Brooy S. (2008) 'Developments in processing to match future mining opportunities', Paper presented at The First International Future Mining Conference, November, Sydney, Australia.

Liker, J.K. (2004) The Toyota Way - Fourteen Management Principles from the World's Greatest Manufacturer, McGraw-Hill, New York. 
Mottola, L., Scoble, M. and Lipsett, M.G. (2011) 'Machine monitoring and automation as enablers of lean mining', Proceedings from Second international Future Mining Conference 2011, 22-23 November, Sydney.

Neumann, P. (2006) Inventory of Tools for Ergonomic Evaluation, Arbetslivsrapport nr 2006:21, Arbetslivsinstitutet, Sweden.

Noort, D. and McCarthy, P. (2008) 'The critical path to automated underground mining', Paper presented at The First International Future Mining Conference, November, Sydney, Australia.

Ranhagen, U. (1995) 'Att arbeta i projekt - om planering och projektering inför större förändringar, Moderna verktyg och metoder', Människa - Miljö - Mål, Arbetarskyddsnämnden, Stockholm.

Revuelta, J., Reyes, F. and Pozo, R. (2008) 'El Teniente new mine level project', Paper presented at The First International Future Mining Conference, November, Sydney, Australia.

Scoble, M. and Laurence, D. (2008) 'Future mining engineers - educational development strategy'. Paper presented at The First International Future Mining Conference, November, Sydney, Australia.

Seedsman, R. (2011) 'Rock mechanics', in Darling, P. (Ed.): SME Mining Engineering Handbook, 3rd ed., Published by SME - 2011, 2 Volumes Hardbound, 1984 pages.

Widzyk-Capehart, E. and Duff, E. (2007) 'Automation: a blessing or a curse? Transferable lessons for the mining industry', Paper presented at The Sixteenth International Symposium on Mine Planning and Equipment Selection (MPES 2007), December, Bangkok, Thailand. 